\title{
Deep brain stimulation for Gilles de la Tourette syndrome in children and youth: a meta-analysis with individual participant data
}

\author{
Marie-Andrée Coulombe, PhD, ${ }^{1}$ Lior M. Elkaim, ${ }^{1}$ Naif M. Alotaibi, MD, MSc, ${ }^{2,3}$ \\ Daniel A. Gorman, MD, ${ }^{4}$ Alexander G. Weil, MD, ${ }^{1,5}$ Aria Fallah, MD, MSc, ${ }^{6}$ Suneil K. Kalia, MD, PhD, ${ }^{2,3}$ \\ Nir Lipsman, MD, PhD, , ${ }^{2,7}$ Andres M. Lozano, MD, PhD, ${ }^{2,3}$ and George M. Ibrahim, MD, PhD2,8

\begin{abstract}
${ }^{1}$ Faculty of Medicine, Université de Montréal, Quebec; ${ }^{2}$ Department of Surgery, University of Toronto; ${ }^{3}$ Division of Neurosurgery, Toronto Western Hospital, Krembil Neuroscience Institute, Toronto; and ${ }^{4}$ Department of Psychiatry, The Hospital for Sick

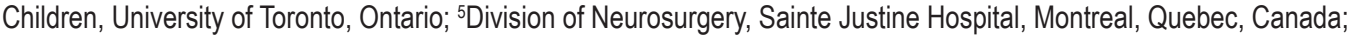
${ }^{6}$ Department of Neurosurgery, UCLA Mattel Children's Hospital, David Geffen School of Medicine at UCLA, Los Angeles, California; 'Division of Neurosurgery, Sunnybrook Health Sciences Centre, Toronto; and ${ }^{7}$ Division of Neurosurgery, The Hospital for Sick Children, The Hospital for Sick Children Research Institute, Program in Neuroscience and Mental Health, Toronto, Ontario, Canada
\end{abstract}

OBJECTIVE Gilles de la Tourette syndrome (GTS) is a disorder characterized by motor and vocal tics. Although by definition the onset of GTS is before age 18 years, clinical trials of deep brain stimulation (DBS) have been conducted only in adults. Using individual participant data (IPD) meta-analysis methodology, the current study investigated the safety and efficacy of DBS as a treatment for GTS in children and youth.

METHODS A systematic review with no date or language restrictions was performed according to the PRISMA (Preferred Reporting Items for Systematic Reviews and Meta-Analyses) statement. Three electronic databases were searched: PubMed, EMBASE, and Web of Science. From 843 articles screened, the IPD of 58 children and youth (ages 12-21 years) extracted from 21 articles were collected and analyzed. A mixed-effects univariable analysis followed by multivariable hierarchical regression was performed using change in the Yale Global Tic Severity Scale (YGTSS) score as the primary outcome and reported measures of comorbidities as secondary outcomes.

RESULTS The authors' results showed an average improvement of $57.5 \% \pm 24.6 \%$ across studies on the YGTSS. They also found that comorbid depression and stimulation pulse width each correlated negatively with outcome $(p<0.05)$. In patients with less severe GTS, greater improvements were evident following thalamic stimulation. More than one-quarter ( $n=16,27.6 \%$ ) of participants experienced side effects, the majority of which were minor.

CONCLUSIONS DBS in the pediatric population may be an effective option with a moderate safety profile for treatment of GTS in carefully selected children and youth. Large, prospective studies with long-term follow-up are necessary to understand how DBS influences tic symptoms and may alter the natural course of GTS in children.

https://thejns.org/doi/abs/10.3171/2018.7.PEDS18300

KEYWORDS Gilles de la Tourette syndrome; deep brain stimulation; neuropsychiatric disorder; functional neurosurgery

$\mathrm{G}$ ILLES de la Tourette syndrome (GTS) is a neuropsychiatric disorder characterized by motor and vocal tics. A tic is a sudden, rapid, recurrent, nonrhythmic movement or vocalization. By definition, onset of the disorder occurs before age 18 years. Typically, tic symptoms have their onset in early childhood, peak dur- ing the prepubertal period, and then gradually decrease during adolescence. ${ }^{3}$ In fact, approximately $75 \%$ of children with GTS will experience remission of their disease or demonstrate considerable improvements in tic severity once brain maturation is complete..$^{19,24,32}$ Although the majority of affected patients are able to function normally

ABBREVIATIONS ADHD = attention-deficit/hyperactivity disorder; DBS = deep brain stimulation; GPi = globus pallidus pars interna; GTS = Gilles de la Tourette syndrome; GTS-QOL = GTS Quality of Life; HDRS = Hamilton Depression Rating Scale; IPD = individual participant data; NA = nucleus accumbens; OCD = obsessive-compulsive disorder; SIB = self-injurious behavior; STAI = State-Trait Anxiety Inventory; Y-BOCS = Yale-Brown Obsessive Compulsive Scale; YGTSS = Yale Global Tic Severity Scale. SUBMITTED May 18, 2018. ACCEPTED July 25, 2018.

INCLUDE WHEN CITING Published online October 26, 2018; DOI: 10.3171/2018.7.PEDS18300. 
and require no treatments beyond psychoeducation and psychosocial support, ${ }^{4}$ some manifest severe and debilitating symptoms that can lead to physical injury, emotional distress, and psychosocial impairment., ${ }^{4,6}$ Furthermore, GTS is frequently associated with comorbidities such as attention-deficit/hyperactivity disorder (ADHD), obsessive-compulsive disorder (OCD), anxiety, depression, and self-injurious behavior (SIB). ${ }^{16,23,47}$ These comorbidities may further contribute to decreased quality of life. ${ }^{17}$

The pathophysiology of GTS is incompletely understood. Involvement of the cortico-striato-thalamo-cortical network is generally described. ${ }^{12,25,36}$ Various investigations have implicated dopamine receptors in the disease pathophysiology, providing a biological rationale for the use of antipsychotic agents. ${ }^{31}$ Alterations in GABA and glutamate neurotransmission have also been reported. The main treatment approaches are evidence-based behavior therapy and pharmacotherapy, including antipsychotic agents, alpha-2 agonists, and other medications. Although these treatments are effective for many patients, some still experience intractable symptoms or cannot tolerate medication side effects. ${ }^{4,6}$

For patients with treatment-resistant tics that are severe and impairing, initial positive experience with ablation of the median and rostral intralaminar thalamus ${ }^{25}$ generated enthusiasm for neuromodulation through deep brain stimulation (DBS). Although DBS has clear advantages over other surgical treatments, ${ }^{34}$ numerous questions remain unanswered, such as the ideal target in GTS. Several putative targets have been described, including the globus pallidus pars interna (GPi), the thalamus, and the nucleus accumbens (NA). ${ }^{45}$

The role of DBS as a treatment for GTS in pediatric populations is a subject of ongoing controversy. Although published guidelines recommend its use primarily in patients 25 years and older, ${ }^{38} \mathrm{DBS}$ has been used successfully in children with GTS as young as 12 years of age. ${ }^{26}$ Authors of the 2011 European guidelines proposed that because tic symptoms often improve or resolve with brain maturation, surgical interventions should be delayed. The authors did not, however, identify inferior outcomes in 11 children younger than 25 years treated with DBS, compared with older cohorts. Given the poor quality of evidence supporting its use, most recent Canadian and American guidelines recommend against the use of DBS in children. ${ }^{39,55}$

In order to address knowledge gaps in our understanding of the safety and efficacy of DBS in young people with GTS, we performed a systematic review and meta-analysis of the published literature involving children and youth (s 21 years). Individual participant data (IPD) were extracted from each case report and series, and a multilevel statistical model was applied to identify putative predictors of treatment response.

\section{Methods}

\section{Search Strategy and Eligibility Criteria}

We applied IPD meta-analysis methodology, following the PRISMA (Preferred Reporting Items for Systematic Reviews and Meta-Analyses) statement, to evaluate the safety and efficacy of DBS for GTS in children. This methodology increases statistical power and is particularly helpful to investigate questions that were not originally addressed in the individual publications. ${ }^{29}$ Our study protocol was developed, but not registered, by authors with content and methodological expertise (G.M.I., N.L., and N.M.A.) prior to conduct of the review.

A systematic review was performed by searching 3 electronic databases: PubMed, EMBASE, and Web of Science. All articles reporting on DBS for pediatric GTS that were published before October 2017, including case reports and cohort studies, were identified. To be included, studies were required to 1) involve pediatric patients (age $\leq 21$ years) living with GTS and treated with DBS; and 2) report outcome by administering the Yale Global Tic Severity Scale (YGTSS) pre- and postoperatively. ${ }^{33}$ Studies were excluded if 1) IPD were not available; or 2) the same patients were presented in different studies (duplicates). Electronic databases were searched using the following search terms: "pediatric deep brain stimulation," "Tourette deep brain stimulation," "Tourette's deep brain stimulation," and "children deep brain stimulation." No language restriction was used.

\section{Data Extraction}

Data were collected independently by 2 reviewers (L.M.E. and M.A.C.), and a third reviewer verified accuracy (G.M.I.) and adjudicated disagreements. Studies were screened for predefined variables, including YGTSS pre- and postsurgery, age at surgery, age at GTS onset, sex, descriptive tic severity (phonetic, motor, coprolalia), number and types of medications tried, family history (tic disorder or other psychiatric disorder), nuclei targeted in DBS, bilateral versus unilateral stimulation, stimulation parameters, reported complications, and follow-up duration. When available, standardized scores describing the severity and changes in comorbid conditions were extracted. These included scores on the Yale-Brown Obsessive Compulsive Scale (Y-BOCS), ${ }_{18}^{18}$ GTS Quality of Life Scale (GTS-QOL), ${ }^{8}$ and State-Trait Anxiety Inventory (STAI). ${ }^{54}$ Measurements of depression were also extracted using a variety of outcome measures, as reported by individual studies (Beck Depression Index, Hamilton Depression Rating Scale [HDRS], ${ }^{22}$ Hospital Anxiety and Depression Scale).

The reference lists of all articles identified were reviewed for any additional articles that met our inclusion and exclusion criteria. We also performed a search of highly published authors on DBS treatment for GTS, based on authorship of adult clinical trials. A list of all articles screened was compiled. All excluded articles underwent adjudication, and specific justifications were noted. All data, particularly studies from the same institution, were reviewed for duplicates. All duplicate publications or participants were removed. In cases of identical cohorts described in more than 1 article, only the article with the longest follow-up time was included. In cases of uncertainty regarding duplicate patients, the authors of the articles were contacted.

\section{Endpoints}

The primary outcome measure in this meta-analysis 


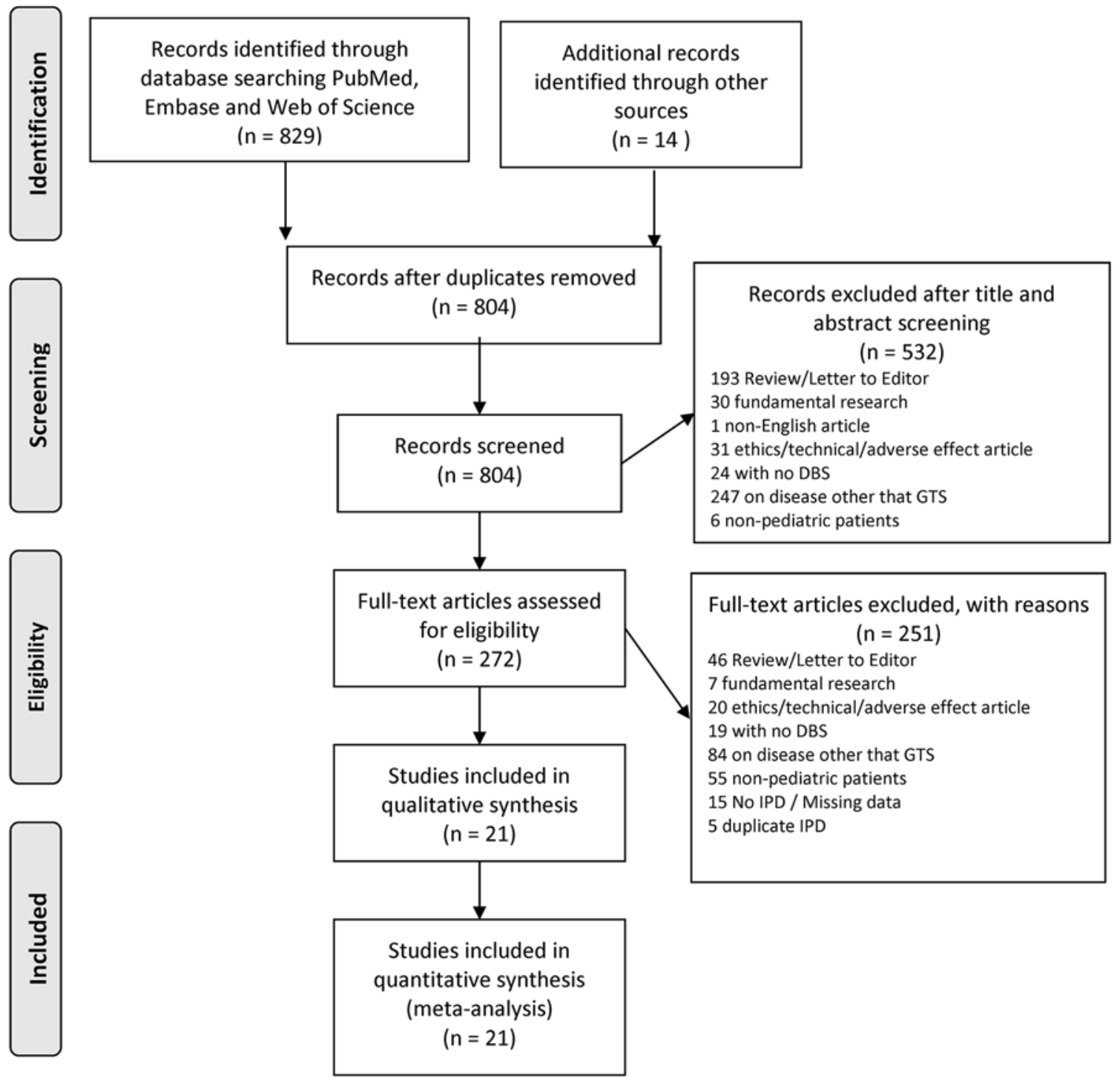

FIG. 1. Search results and included articles as per the PRISMA guidelines.

was the percentage change in the YGTSS total score (preoperatively vs last follow-up). The scores were adjusted such that a change with a positive value reflected postoperative improvement. Secondary outcomes were changes in comorbidities of GTS, measured using the Y-BOCS, the STAI, and the HDRS, as reported by individual studies and pooled in the IPD database.

\section{Risk of Bias Assessment and Quality of Evidence}

Since all patients were observational, unmatched case series and reports, risk of bias and quality of evidence were considered "high risk of bias" and "low to very low quality of evidence" as per the GRADE (Grading of Recommendations Assessment, Development and Evaluation) tool. ${ }^{21}$

\section{Statistical Analysis}

Univariable mixed-effects generalized linear models were performed for each covariate of interest. Covariates with $\mathrm{p}<0.05$ on mixed-effects univariable analysis were included in a hierarchical multivariable mixed-effects model. All analyses were performed using R statistical software (RStudio version 0.99.484).

\section{Results \\ Search Results}

The search strategy identified 829 articles. Fourteen additional articles were added following review of reference lists, resulting in a total of 843 articles. Thirty-nine duplicates were removed, leaving 804 articles to be screened. Of these, 532 articles were excluded through title and abstract screening. The 272 remaining articles underwent full-length review. From these, 251 articles did not meet inclusion criteria or met exclusion criteria. A total of 21 articles reporting IPD for 58 patients were included (Fig. 1). There were 10 case reports and 11 case series. There were no controlled or open trials identified. A complete description of each study is included in Table 1. 


\section{Individual Participant Data}

Demographic information for all IPD of treated children and youth is presented in Table 2 . The patients were on average $17.9 \pm 2.7$ years old (range 12-21 years) and had onset of their tics at a mean age of $7.4 \pm 3.4$ years. Almost three-quarters $(72.4 \%)$ had at least 1 psychiatric comorbidity (ADHD, OCD, anxiety, or depression disorders). A substantial minority (27\%) also manifested patterns of SIB. Overall, the cohort had a mean preoperative YGTSS score of $78.3 \pm 17.5$ (ranging from 25 to 100). Six patients had a score lower than 50 .

Electrodes were placed in the GPi in 33 patients (anteromedial GPi in 6 patients, posteroventral region GPi in 1 patient, and exact localization not specified for 26 patients). The thalamus was targeted in 24 youths: the centromedian-parafascicular and ventralis oralis complex of the thalamus (CM-Pfc) in 20, fields of Forel in 1, and exact localization not specified for 3 . Finally, 1 patient underwent DBS implantation in the centromedian-parafascicular thalamic complex, which improved tic severity, but also had electrodes implanted in GPi and later NA, to target OCD specifically. The specific stimulation parameters used are presented in Table 3. Stimulation parameters differed between patients and were selected at the discretion of the treating neurosurgeon.

\section{Primary and Secondary Outcomes Following DBS}

Following DBS, the mean percentage change on our primary outcome measure, the YGTSS, was $57.5 \% \pm$ $24.6 \%$ ( $\mathrm{p}<0.001$ ) over a mean follow-up period of 34.2 \pm 23.4 months (range 3-95 months). Nearly all children (96.6\%) demonstrated some improvement in tic symptoms, with $91.4 \%$ and $64.0 \%$ showing greater than $20 \%$ and $50 \%$ improvement, respectively.

The pre- and postoperative scores on the YGTSS, YBOCS, STAI, and GTS-QOL are presented in Table 4. Significant improvements were also identified on 2 secondary outcome measures, the Y-BOCS and STAI. Moreover, changes in Y-BOCS, STAI, and GTS-QOL scores were significantly associated with percentage change in the YGTSS.

\section{Moderator Analyses}

On univariable hierarchical mixed-effects analysis, comorbid anxiety, comorbid depression, and low pulse width of stimulation were each significantly associated with less improvement in YGTSS scores (Tables 2 and 3). On hierarchical multivariable analysis, the associations with comorbid depression and pulse width remained significant, whereas the association with comorbid anxiety did not (Table 5).

Patients with less severe GTS (defined by excluding the most severe quartile on the basis of the preoperative YGTSS score) were evaluated as a separate cohort in order to account for a potential ceiling effect of treatment. Within this cohort, thalamic stimulation (as opposed to GPi stimulation) was associated with greater improvements in

TABLE 1. Articles included in meta-analysis

\begin{tabular}{|c|c|c|c|c|c|}
\hline Authors \& Year & Journal & $\begin{array}{l}\text { Total No. of } \\
\text { Patients }\end{array}$ & $\begin{array}{l}\text { No. of Patients } \\
\text { Included }\end{array}$ & $\begin{array}{c}\text { DBS Target } \\
\text { (GPi/thalamus) }\end{array}$ & $\begin{array}{c}\text { Age Range of } \\
\text { Included Patients, yrs }\end{array}$ \\
\hline Dwarakanath et al., 2017 & Neurol India & 1 & 1 & $1 / 0$ & 18 \\
\hline Hauseux et al., 2017 & Eur J Paediatr Neurol & 3 & 3 & $3 / 0$ & $12-18$ \\
\hline Dowd et al., 2018 & J Neurosurg & 13 & 10 & $10 / 0$ & $16-21$ \\
\hline Testini et al., 2016 & Mayo Clin Proc & 12 & 3 & $1 / 2$ & $17-18$ \\
\hline Servello et al., 2016 & Neurosurgery & 48 & 4 & $3 / 1$ & $12-20$ \\
\hline Huys et al., 2016 & Biol Psychiatry & 8 & 1 & $0 / 1$ & 19 \\
\hline Zekaj et al., 2015 & Surg Neurol Int & 1 & 1 & $0 / 1$ & 17 \\
\hline Patel \& Jimenez-Shahed, 2014 & Parkinsonism Relat Disord & 1 & 1 & $1 / 0$ & 21 \\
\hline Sachdev et al., 2014 & PLoS One & 17 & 5 & $4 / 1$ & $17-19$ \\
\hline Nair et al., 2014 & J Clin Neurosci & 4 & 2 & $2 / 0$ & $15-21$ \\
\hline Huasen et al., 2014 & Mov Disord & 1 & 1 & $1 / 0$ & 19 \\
\hline Zhang et al., 2014 & Mayo Clin Proc & 13 & 9 & $9 / 0$ & $16-21$ \\
\hline Wårdell et al., 2015 & Neuromodulation & 5 & 2 & $2 / 0$ & $19-21$ \\
\hline Massano et al., 2013 & J Neurol & 1 & 1 & $1 / 0$ & 14 \\
\hline Motlagh et al., 2013 & Tremor Other Hyperkinet Mov (N Y) & 8 & 3 & $1 / 2$ & $16-19$ \\
\hline Savica et al., 2012 & Mayo Clin Proc & 3 & 1 & $0 / 1$ & 17 \\
\hline Porta et al., 2012 & Acta Neurochir (Wien) & 18 & 4 & $2 / 2$ & $17-20$ \\
\hline Kaido et al., 2011 & Neuromodulation & 3 & 3 & $1 / 2$ & $19-21$ \\
\hline Dueck et al., 2009 & Neuropediatrics & 1 & 1 & $1 / 0$ & 16 \\
\hline Shahed et al., 2007 & Neurology & 1 & 1 & $1 / 0$ & 16 \\
\hline Neudorfer et al., 2017 & Front Hum Neurosci & 2 & 1 & $0 / 1$ & 19 \\
\hline
\end{tabular}

\footnotetext{
${ }^{*}$ Number of patients meeting inclusion criteria.
} 
TABLE 2. Individual participant characteristics and univariable analysis for studies reporting change in YGTSS $(n=58)$

\begin{tabular}{|c|c|c|c|c|c|}
\hline Variable & Value* $^{*}$ & No. of Patients† & No. of Studies $\ddagger$ & Estimate (SE) & t-Value \\
\hline Age at onset (yrs) & $7.4(3.4)$ & 44 & 15 & $0.3(1.2)$ & 0.3 \\
\hline Age at surgery (yrs) & $17.9(2.7)$ & 58 & 21 & $-1.4(1.1)$ & -1.2 \\
\hline Male sex & $35(78 \%)$ & 45 & 18 & $11.1(8.0)$ & 1.4 \\
\hline Duration (yrs) & $10.5(3.1)$ & 44 & 15 & $-1.0(1.2)$ & -0.8 \\
\hline \multicolumn{6}{|l|}{ Family history (vs none) } \\
\hline Tic disorder & $6(60 \%)$ & \multirow{2}{*}{10} & \multirow{2}{*}{7} & $1.5(25.5)$ & 0.1 \\
\hline Other psychiatric disorder & $1(10 \%)$ & & & $12.5(41.7)$ & 0.3 \\
\hline \multicolumn{6}{|l|}{ Comorbidities } \\
\hline ADHD & $22(46 \%)$ & 48 & 17 & $-0.5(7.4)$ & -0.1 \\
\hline Anxiety & $13(25 \%)$ & 52 & 18 & $-17.3(8.3)$ & $-2.1 \S$ \\
\hline Depression & $22(42 \%)$ & 52 & 18 & $-17.4(7.0)$ & $-2.5 \S$ \\
\hline SIB & $13(27 \%)$ & 48 & 17 & $-11.5(9.0)$ & -1.3 \\
\hline OCD & $33(63 \%)$ & 52 & 18 & $-5.6(7.1)$ & -0.8 \\
\hline \multicolumn{6}{|l|}{ Preop status } \\
\hline YGTSS & $78.3(17.5)$ & 58 & 21 & $-0.1(0.2)$ & -0.3 \\
\hline GTS-QOL & $47.1(14.4)$ & 15 & 3 & $-0.3(0.5)$ & -0.7 \\
\hline Y-BOCS & $17.1(9.0)$ & 29 & 10 & $-0.3(0.5)$ & -0.7 \\
\hline \multicolumn{6}{|l|}{ Severity of disease } \\
\hline No. of drugs attempted & $6.8(3.2)$ & 26 & 14 & $-2.5(1.9)$ & -1.3 \\
\hline Motor tics (complex vs simple) & $28(93 \%)$ & 30 & 15 & $5.7(16.3)$ & 0.4 \\
\hline Vocal tics (complex vs simple) & $5(33 \%)$ & 15 & 7 & $18.6(18.4)$ & 1.0 \\
\hline Coprolalia & $11(44 \%)$ & 25 & 13 & $3.8(10.6)$ & 0.4 \\
\hline Follow-up duration (mos) & $34.2(23.4)$ & 38 & 15 & $0.1(0.2)$ & 0.8 \\
\hline$\%$ change in YGTSS total score & $57.5(24.6)$ & 58 & 21 & & \\
\hline
\end{tabular}

*Values are presented as the mean (SD) or number of patients meeting the variable (\%).

† Number of patients for whom the information was provided.

$\ddagger$ Number of studies providing the information.

$\S$ Significant association with outcome on univariable analysis.

YGTSS score on univariate analysis (GPi [mean \pm SEM]: $53.0 \% \pm 4.7 \%$, thalamus [mean \pm SEM] : $68.6 \% \pm 5.8 \% ; p$ $=0.0387$, Mann-Whitney test [Fig. 2]).

\section{Adverse Events and Safety}

Over one-quarter $(n=16,27.6 \%)$ of participants experi- enced side effects (Table 6). These included neck stiffness, headaches, blurred vision, decreased visual acuity, lightheadedness, nausea, decreased memory, and dizziness. Dysarthria, anxiety, and suicidal thoughts were noted in 2 patients. Other complications included tremor, disinhibition, agitation, and mild paresthesia. However, most side

TABLE 3. DBS parameters and univariable analysis for studies reporting change in YGTSS

\begin{tabular}{|c|c|c|c|c|c|}
\hline Variable & No. of Patients Meeting Variable (\%) & No. of Patients* & No. of Studies† & Estimate (SE) & $\mathrm{t}$-Value \\
\hline \multicolumn{6}{|l|}{ DBS target } \\
\hline GPi vs non-GPi & $33(57 \%)$ & 58 & 21 & $7.4(8.1)$ & 0.9 \\
\hline Thalamus vs nonthalamus & $25(43 \%)$ & 58 & 21 & $12.7(7.2)$ & 1.8 \\
\hline GPi vs thalamus & $33(59 \%)$ & 58 & 21 & $14.0(7.6)$ & 1.8 \\
\hline \multicolumn{6}{|l|}{ Stimulation parametersł } \\
\hline Frequency (<130 vs $\geq 130 \mathrm{~Hz})$ & $39(75 \%)$ & 52 & 19 & $-3.3(10.0)$ & -0.3 \\
\hline Amplitude (<3.25 vs $\geq 3.25 \mathrm{~V})$ & $25(52 \%)$ & 48 & 18 & $-8.7(6.5)$ & -1.3 \\
\hline Pulse width (<120 vs $\geq 120 \mu \mathrm{sec})$ & $25(52 \%)$ & 48 & 18 & $-18.3(7.6)$ & $-2.4 \S$ \\
\hline
\end{tabular}

* Number of patients for whom the information was provided.

† Number of studies providing the information.

$\ddagger$ Parameters dichotomized by median values; in cases of discrepancy between right and left side, the mean was calculated.

$\S$ Significant association with outcome on univariable analysis. 
TABLE 4. Changes in comorbidities of GTS following DBS

\begin{tabular}{|c|c|c|c|c|c|}
\hline Tourette's Patients $(n=58)$ & No. of Patients & Mean \pm SD & Range & t-Score & p Value \\
\hline \multicolumn{6}{|l|}{ YGTSS } \\
\hline Severity preop & 31 & $40.1 \pm 8.5$ & 20 to 50 & \multirow{2}{*}{15.93} & \multirow{2}{*}{$<0.001$} \\
\hline Severity postop & 31 & $18.2 \pm 11.2$ & 0 to 42 & & \\
\hline Severity $\%$ change & 31 & $55.7 \pm 24.7$ & 6.67 to 100 & & \\
\hline Impairment preop & 39 & $41.9 \pm 9.0$ & 10 to 50 & \multirow{2}{*}{11.93} & \multirow{2}{*}{$<0.001$} \\
\hline Impairment postop & 39 & $16.4 \pm 11.7$ & 0 to 40 & & \\
\hline Impairment $\%$ change & 29 & $60.1 \pm 27.2$ & 20 to 100 & & \\
\hline Total score preop & 58 & $78.3 \pm 17.5$ & 25 to 100 & \multirow{2}{*}{11.96} & \multirow{2}{*}{$<0.001$} \\
\hline Total score postop & 58 & $33.4 \pm 21.8$ & 0 to 86 & & \\
\hline Total score $\%$ change & 58 & $57.5 \pm 24.6$ & 0 to 100 & & \\
\hline \multicolumn{6}{|l|}{ Y-BOCS } \\
\hline Total score preop & 31 & $15.9 \pm 9.8$ & 0 to 30 & \multirow{2}{*}{3.657} & \multirow{2}{*}{$<0.001$} \\
\hline Total score postop & 31 & $10.7 \pm 10.0$ & 0 to 39 & & \\
\hline Total score $\%$ change & 31 & $30.6 \pm 44.7$ & -75 to 100 & & \\
\hline \multicolumn{6}{|l|}{ GTS-QOL } \\
\hline Total score preop & 14 & $47.1 \pm 14.4$ & 20 to 70 & \multirow{2}{*}{1.184} & \multirow{2}{*}{0.256} \\
\hline Total score postop & 14 & $39.2 \pm 22.3$ & 13 to 80 & & \\
\hline Total score $\%$ change & 14 & $6.1 \pm 61.3$ & -100 to 77 & & \\
\hline \multicolumn{6}{|l|}{ STAI } \\
\hline Total score preop & 8 & $47.1 \pm 8.4$ & 38 to 60 & \multirow{2}{*}{5.212} & \multirow{2}{*}{$<0.001$} \\
\hline Total score postop & 8 & $27.5 \pm 7.4$ & 20 to 39 & & \\
\hline Total score $\%$ change & 8 & $40.2 \pm 20.1$ & -2.6 to 58 & & \\
\hline \multicolumn{6}{|l|}{ HDRS } \\
\hline Total score preop & 8 & $10.4 \pm 9.0$ & 0 to 27 & \multirow{2}{*}{1.441} & \multirow{2}{*}{0.193} \\
\hline Total score postop & 8 & $6.3 \pm 8.0$ & 0 to 18 & & \\
\hline Total score $\%$ change & 8 & $39.9 \pm 63.3$ & -80 to 100 & & \\
\hline
\end{tabular}

Paired t-test; $p$ value was set to $p<0.007$ to account for multiple comparisons ( $a$ /number of comparisons).

effects are reversible and present only at high voltages of stimulation. A substantial minority $(\mathrm{n}=8,13.8 \%)$ experienced surgical complications following device installation (Table 6). These included infections in 3 patients, abdominal wall hematoma, wound revision, and hardware malfunction. Finally, 6 devices were removed for various reasons, as outlined in Table 6. Of note, not all removals were related to complications; in 3 of 6 cases the patient improved sufficiently such that DBS was no longer felt necessary.

One patient, originally described in a case report by Duits et al. but not included in our analysis due to missing primary endpoint data, died 3 years after surgery. ${ }^{14} \mathrm{In}$

TABLE 5. Multivariable hierarchical mixed-effects analysis of covariates associated with changes in YGTSS using independent participant data

\begin{tabular}{lccc}
\hline \multicolumn{1}{c}{ Variable } & $\begin{array}{c}\text { Estimate } \\
\text { (SE) }\end{array}$ & t-Value & $\begin{array}{c}\text { Model Coefficient } \\
(95 \% \mathrm{CI})\end{array}$ \\
\hline Comorbid anxiety & $-9.5(8.9)$ & -1.1 & $-9.5(-26.6$ to 7.5$)$ \\
\hline Comorbid depression & $-19.0(7.8)$ & $-2.4^{*}$ & $-19.0(-34.0$ to -4.1$)$ \\
\hline Pulse width & $-17.3(6.1)$ & $-2.8^{*}$ & $-17.3(-28.9$ to -5.6$)$ \\
\hline
\end{tabular}

* Significant association with outcome. this extreme example, the 20-year-old patient developed abrupt hypertonia and difficulty swallowing and refrained from hospital admission for intravenous infusion; she subsequently died at a palliation facility.

\section{Discussion}

The current IPD meta-analysis is the first to investigate the efficacy and safety of DBS as a treatment for GTS in children and youth and provides a comprehensive synthesis of the published literature on DBS in this population. ${ }^{56}$ DBS has been previously reported in adult populations as an effective treatment, reducing tic severity and improving comorbid symptoms, such as OCD, anxiety, and depression. ${ }^{46}$ Although DBS is an established treatment for other pediatric conditions, such as dystonia, ${ }^{34}$ its application to GTS remains controversial given the limited evidence to date, the potential risks, and the consideration that even without treatment, the majority of affected children experience improvement in their tics during adolescence.

Overall, we found that DBS appeared to improve tic severity, irrespective of the anatomical target for stimulation. Our IPD analysis revealed that $91.4 \%$ of children demonstrated YGTSS score improvements greater than 20\%, with $64 \%$ showing improvement greater than $50 \%$. These 


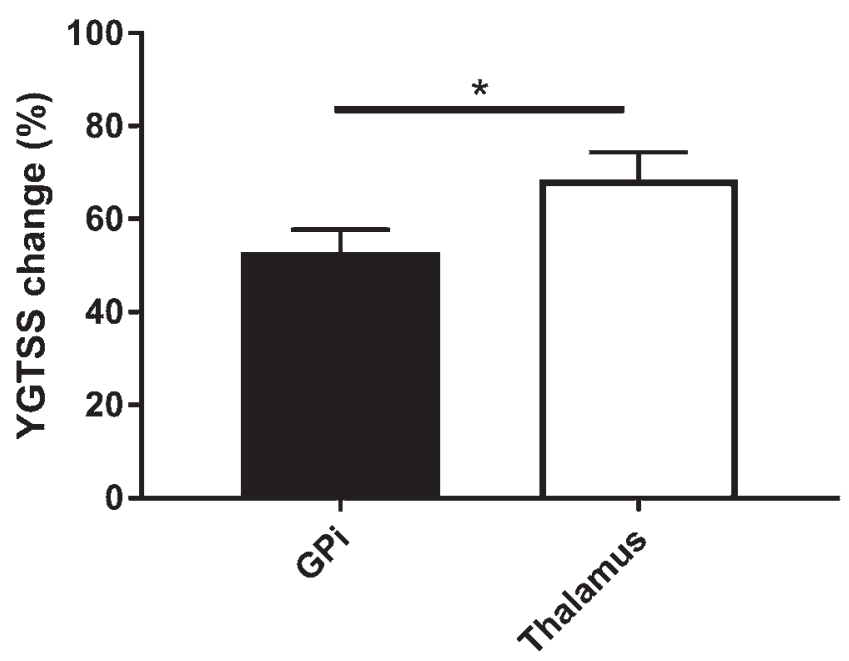

FIG. 2. Greater improvements in YGTSS score after thalamic DBS compared with GPi DBS in children and youth with less severe (excluding the most severe quartile, based on preoperative YGTSS score) GTS on univariate analysis. Bars indicate the mean and error bars the SEM.

uncontrolled data, drawn from case reports and case series, provide preliminary support for the efficacy of DBS treatment in youth. Whether DBS alters the natural history of GTS in young patients remains unclear. Clinical evidence for the role of DBS in GTS should be complemented by research efforts to distinguish the minority of children who will have persistent, debilitating tics and may benefit from DBS earlier in the disease course from the majority who will improve over time.

In the literature, a variety of targets have been utilized, and it remains unclear which is the most effective for GTS. ${ }^{45}$ In this study, the anatomical target of DBS was not significantly associated with tic symptom improvement, as both pallidal and thalamic stimulation appeared effective (Table 3). These findings are consistent with previous observations in adults from Baldermann and colleagues. ${ }^{2,9}$ When we exclude the most severely impaired quartile of children (YGTSS score lower than 92/100), the thalamus was a significantly better target than the GPi, at least on univariable analysis. This may reflect the widespread cortical circuitry involved in the pathogenesis of GTS..$^{57}$

Our findings also suggested that stimulation parameters might influence clinical outcomes. We observed that pulse width correlated with tic improvement measured on the YGTSS. This correlation potentially has important clinical implications, as currently there are no precise guidelines in the published literature regarding the frequency and pulse length of stimulation. The correlation was not observed in previous studies, and stimulation parameters are generally set individually. ${ }^{2}$ These findings further highlight the importance of involvement of an expert in DBS programming when considering DBS for GTS..$^{55}$

DBS for GTS in children carries a moderate risk profile. The complications noted include hardware malfunction, battery changes, and infections. From the pooled data set, 8 children had some form of surgical complications. Only 2 of them resulted in the removal of the electrodes. In a previous study, Servello and colleagues reviewed 531
TABLE 6. Adverse events in GTS children treated with DBS $(n=58)$

\begin{tabular}{|c|c|c|}
\hline & $\begin{array}{l}\text { No. of } \\
\text { Pts (\%) }\end{array}$ & Notes \\
\hline \multicolumn{3}{|l|}{ Surgical complications } \\
\hline Total & $8(13.8)$ & \\
\hline Infection & $3(5.2)$ & 2 of 3 had their lead removed \\
\hline Hematoma & $1(1.7)$ & \\
\hline $\begin{array}{l}\text { Subcutaneous } \\
\text { hydrops }\end{array}$ & $1(1.7)$ & \\
\hline $\begin{array}{l}\text { Hardware mal- } \\
\text { function }\end{array}$ & $1(1.7)$ & Retitration needed \\
\hline Lead tip cyst & $1(1.7)$ & Lead removed \\
\hline Lead fracture & $1(1.7)$ & Lead replacement \\
\hline $\begin{array}{l}\text { Needed wound } \\
\text { revision }\end{array}$ & $2(3.4)$ & After 6 yrs \& after 1 mo \\
\hline \multicolumn{3}{|l|}{ Side effects } \\
\hline Total & $16(27.6)$ & \\
\hline Tension headache & $1(1.7)$ & \\
\hline $\begin{array}{l}\text { Worsening of } \\
\text { preexisting } \\
\text { tremor }\end{array}$ & $2(3.4)$ & \\
\hline $\begin{array}{l}\text { Transient blurring } \\
\text { of vision }\end{array}$ & $5(8.6)$ & $\begin{array}{l}\text { At the initiation of stimulation or at } \\
\text { certain voltage amplitude }\end{array}$ \\
\hline Dizziness & $2(3.4)$ & Resulting from voltage increase \\
\hline $\begin{array}{r}\text { Decreased } \\
\text { memory }\end{array}$ & $1(1.7)$ & \\
\hline $\begin{array}{l}\text { Seizure-like } \\
\text { episode }\end{array}$ & $1(1.7)$ & One occurrence \\
\hline Suicidal thoughts & $1(1.7)$ & \\
\hline $\begin{array}{l}\text { Decline of atten- } \\
\quad \text { tion \& mental } \\
\text { flexibility }\end{array}$ & $1(1.7)$ & \\
\hline Neck tightness & $1(1.7)$ & \\
\hline Paresthesia (mild) & $1(1.7)$ & Stimulation related \\
\hline Light headedness & $1(1.7)$ & Stimulation related \\
\hline Parkinsonism & $1(1.7)$ & \\
\hline Increased OCD & $1(1.7)$ & \\
\hline Anxiety & $3(5.2)$ & \\
\hline Agitation & $2(3.4)$ & \\
\hline $\begin{array}{r}\text { Disturbance of } \\
\text { eye mobility }\end{array}$ & $1(1.7)$ & \\
\hline Dysarthria & $4(6.9)$ & \\
\hline Nausea & $1(1.7)$ & At high intensity \\
\hline \multicolumn{3}{|l|}{ Lead removal } \\
\hline Total & $6(10.3)$ & \\
\hline $\begin{array}{l}\text { After } 5 \text { yrs \& } 7 \\
\text { mos }\end{array}$ & & $\begin{array}{l}\text { For personal reasons; stimulation } \\
\text { increased anxiety \& OCD }\end{array}$ \\
\hline $\begin{array}{l}\text { After } 3 \text { yrs \& } 2 \\
\quad \text { mos }\end{array}$ & & $\begin{array}{l}\text { Infection, rejection of pouch, pos- } \\
\text { sibly resulting from excessive } \\
\text { self-grooming }\end{array}$ \\
\hline After 5 yrs & & $\begin{array}{l}\text { Symptoms almost completely } \\
\text { resolved }\end{array}$ \\
\hline
\end{tabular}

CONTINUED ON PAGE 243 » 
» CONTINUED FROM PAGE 242

TABLE 6. Adverse events in GTS children treated with DBS $(n=58)$

\begin{tabular}{|c|c|c|}
\hline & $\begin{array}{l}\text { No. of } \\
\text { Pts (\%) }\end{array}$ & Notes \\
\hline \multicolumn{3}{|l|}{$\begin{array}{l}\text { Lead removal (contin- } \\
\qquad \text { ued) }\end{array}$} \\
\hline Total (continued) & $6(10.3)$ & \\
\hline After 4 yrs & & $\begin{array}{l}\text { Pt had sustained benefit \& re- } \\
\text { ported having "a normal life" }\end{array}$ \\
\hline After 3 yrs & & $\begin{array}{l}\text { No aggravation of symptoms \& } \\
\text { stable }\end{array}$ \\
\hline After 2 yrs & & $\begin{array}{l}\text { Lead fracture w/ replacement; } \\
\text { infection of the new electrode } \\
\text { followed by its removal; reim- } \\
\text { plantation } 4 \text { mos later, then an } \\
\text { aseptic cyst appeared on the tip } \\
\text { of the electrode, which lead to } \\
\text { its removal (unilat removal) }\end{array}$ \\
\hline $\begin{array}{l}\text { Part-time } \\
\text { activation }\end{array}$ & & $\begin{array}{l}\text { To spare the battery \& decrease } \\
\text { side effect }\end{array}$ \\
\hline
\end{tabular}

$\mathrm{Pt}=$ patient.

DBS implantation procedures done in 272 patients. They observed a greater prevalence of infections and complications in patients with GTS (18\% in GTS vs $3.7 \%$ overall) compared to other movement disorders, ${ }^{51}$ perhaps as a result of a compromised immune system or compulsive touching of the wound. Various articles alluded to the latter, highlighting the occurrence of behaviors such as "too much self-grooming," and patients "compulsively push[ing] on IPG for four weeks," or "picking at their incision." In the current study, the rate of infection was $5.2 \%$, which, albeit lower than Servello and colleagues' proportions, remains higher than that of reports in other pediatric populations. For example, in a meta-analysis of 307 children with dystonia, 11 infections were noted $(3.6 \%$ infection rate). ${ }^{19}$ The risks of complication related to the intervention, however, continue to decrease with advances in surgical techniques, ${ }^{5,29}$ Worsening of symptoms or unexplained new symptoms have been described. In one case described by Duits et al., ${ }^{14}$ a 20 -year-old female patient had hypertonia and dysphagia following DBS, which ultimately led to her death. Overall, $27.6 \%$ of the participants described some side effects, generally described as mild and related to the activation or the voltage amplitude of the stimulation.

\section{Role of Comorbidities and SIB}

Psychiatric comorbidities are common in GTS. In our IPD database, $72.4 \%$ of children manifested at least 1 comorbidity, most frequently OCD, followed by ADHD and depression. Compared with the statistics of the International Tourette Deep Brain Stimulation Database and Registry (https://tourettedeepbrainstimulationregistry.ese. ufhealth.org), we observed a slightly higher percentage of patients with OCD and ADHD, a lower percentage of patients with anxiety and depression, and a similar percent- age of patients with SIB. From a descriptive perspective, many studies reported significant improvement of comorbid symptoms. However, in some cases DBS increased OCD, anxiety, and depression symptoms (Table 6).

In secondary analyses we found that the presence of comorbid anxiety and depression was each inversely associated with change in YGTSS score when we did not control for covariates. However, only depression remained inversely associated with change in YGTSS score when controlling for covariates. These results differ from previous findings in adults. ${ }^{36}$ Interestingly, significant associations were identified between change in YGTSS score and change in Y-BOCS, STAI, and GTS-QOL scores. This result provides additional support to previous findings that patients with severe GTS are prone to increased stress and decreased quality of life. ${ }^{7,20}$ It was also suggested that DBS could influence OCD symptoms, anxiety, and depression, which could greatly influence the patient's quality of life, independent of its effects on tics. ${ }^{41}$

Our results showed that $27 \%$ of patients had a history of SIB, but we did not have sufficient data to measure improvements. In the adult literature, there are reports of improvement of SIB following thalamic and NA DBS. ${ }^{1,59}$ In addition, many studies on Lesch-Nyhan disease showed good efficacy of pallidal stimulation for improvement of SIB. ${ }^{44}$

\section{Limitations}

Our study has several limitations. First, the absence of a control cohort prevents inferences about whether DBS alters the natural history of GTS in youth. Indeed, the absence of controls raises the question of whether the initial improvement in tic symptoms is due to DBS or instead reflects the natural waxing and waning of tics, the placebo effect, or other factors. As such, the efficacy of DBS in youth with GTS remains uncertain. Second, most articles were case reports or case series, in which validity and specificity of information were sometimes questionable. However, several articles included in this meta-analysis recruited sizable cohorts and included years of follow-up using validated instruments. These study designs are still prone to selection bias and lack internal validity due to the absence of a control group, as previously mentioned. The differences in the quality of the data between these large cohorts and smaller case reports/series were often details surrounding adverse events. Similarly, heterogeneous reporting of primary and secondary outcomes led to the exclusion of some articles describing the use of DBS in children and youth. Third, as with many meta-analyses, publication bias limits the interpretability of our findings. It is possible that negative studies of DBS in children were not published. Fourth, sparse data are available to guide the administration of DBS in youth with GTS, including optimal timing of the intervention, ideal anatomical targets, and stimulation parameters. Importantly, prospective, longitudinal multicenter databases with long-term follow-up are required to further elucidate the role of DBS for children with GTS.

\section{Ethical Perspective in Pediatric DBS for GTS}

Decisions regarding treatment of children and youth 
with DBS are complex and value-laden..$^{10,50}$ Despite the increasing popularity of DBS in adult populations, its use in younger patients is limited for multiple reasons. Evidence for efficacy is limited, observed improvements are variable, and long-term effects are unknown. ${ }^{52}$ There are multiple risks, including those related to hardware malfunction, battery changes, and infection. The risk-to-benefit profile must be weighed for each patient individually. At minimum, requirements for DBS in children and youth should include demonstration of treatment resistance, exclusion of secondary causes, and the potential for physical injury. Particular caution should be exercised with children and younger adolescents, where there is still a good likelihood that the tics will improve as a function of their natural course. Involvement of a multidisciplinary team and a comprehensive informed consent discussion are essential. Authors also have often suggested the involvement of institutional ethics committees, particularly in pediatric cases. ${ }^{38,50}$

\section{Conclusions}

In the current IPD meta-analysis based on uncontrolled case reports and case series, the use of DBS for the treatment of GTS in youth was associated with clinically significant improvements in tic severity. Pallidal and thalamic stimulation both led to good outcomes, but thalamic stimulation had greater effect in less severely affected youth. Higher depression scores and low pulse width of stimulation were each associated with less improvement in tics. A sizable minority of patients had adverse events related to the surgery, or to the stimulation intensity. These adverse events led, in few cases, to the removal of the electrodes. Further research involving multicenter databases and long-term, prospective follow-up is required to clarify the benefits and risks of DBS in youth with GTS, establish potential indications and timing for the intervention, and elucidate precise anatomical targets and stimulation parameters in order to personalize the procedure for specific symptoms in patients.

\section{References}

1. Ackermans L, Duits A, Temel Y, Winogrodzka A, Peeters F, Beuls EA, et al: Long-term outcome of thalamic deep brain stimulation in two patients with Tourette syndrome. J Neurol Neurosurg Psychiatry 81:1068-1072, 2010

2. Baldermann JC, Schüller T, Huys D, Becker I, Timmermann L, Jessen F, et al: Deep brain stimulation for Tourette-syndrome: a systematic review and meta-analysis. Brain Stimul 9:296-304, 2016

3. Bloch MH, Leckman JF: Clinical course of Tourette syndrome. J Psychosom Res 67:497-501, 2009

4. Bloch MH, Peterson BS, Scahill L, Otka J, Katsovich L, Zhang H, et al: Adulthood outcome of tic and obsessivecompulsive symptom severity in children with Tourette syndrome. Arch Pediatr Adolesc Med 160:65-69, 2006

5. Buhmann C, Huckhagel T, Engel K, Gulberti A, Hidding U, Poetter-Nerger M, et al: Adverse events in deep brain stimulation: a retrospective long-term analysis of neurological, psychiatric and other occurrences. PLoS One 12:e0178984, 2017

6. Burd L, Kerbeshian PJ, Barth A, Klug MG, Avery PK, Benz B: Long-term follow-up of an epidemiologically defined cohort of patients with Tourette syndrome. J Child Neurol 16:431-437, 2001

7. Cavanna AE, David K, Orth M, Robertson MM: Predictors during childhood of future health-related quality of life in adults with Gilles de la Tourette syndrome. Eur J Paediatr Neurol 16:605-612, 2012

8. Cavanna AE, Schrag A, Morley D, Orth M, Robertson MM, Joyce E, et al: The Gilles de la Tourette syndrome-quality of life scale (GTS-QOL): development and validation. Neurology 71:1410-1416, 2008

9. Deeb W, Rossi PJ, Porta M, Visser-Vandewalle V, Servello D, Silburn P, et al: The international deep brain stimulation registry and database for Gilles de la Tourette syndrome: how does it work? Front Neurosci 10:170, 2016

10. DiFrancesco MF, Halpern CH, Hurtig HH, Baltuch GH, Heuer GG: Pediatric indications for deep brain stimulation. Childs Nerv Syst 28:1701-1714, 2012

11. Dowd RS, Pourfar M, Mogilner AY: Deep brain stimulation for Tourette syndrome: a single-center series. J Neurosurg 128:596-604, 2018

12. Draper A, Stephenson MC, Jackson GM, Pépés S, Morgan PS, Morris PG, et al: Increased GABA contributes to enhanced control over motor excitability in Tourette syndrome. Curr Biol 24:2343-2347, 2014

13. Dueck A, Wolters A, Wunsch K, Bohne-Suraj S, Mueller JU, Haessler F, et al: Deep brain stimulation of globus pallidus internus in a 16-year-old boy with severe Tourette syndrome and mental retardation. Neuropediatrics 40:239-242, 2009

14. Duits A, Ackermans L, Cath D, Visser-Vandewalle V: Unfavourable outcome of deep brain stimulation in a Tourette patient with severe comorbidity. Eur Child Adolesc Psychiatry 21:529-531, 2012

15. Dwarakanath S, Hegde A, Ketan J, Chandrajit P, Yadav R, Keshav K, et al: "I swear, I can't stop it!"-a case of severe Tourette's syndrome treated with deep brain stimulation of anteromedial globus pallidus interna. Neurol India 65:99_ 102,2017

16. Eapen V, Snedden C, Črnčec R, Pick A, Sachdev P: Tourette syndrome, co-morbidities and quality of life. Aust N Z J Psychiatry 50:82-93, 2016

17. Elkaim LM, Alotaibi NM, Sigal A, Alotaibi HM, Weil AG, Wang AC, et al: Deep brain stimulation for pediatric dystonia: a meta-analysis with individual participant data. Dev Med Child Neurol [in press], 2018

18. Goodman WK, Price LH, Rasmussen SA, Mazure C, Fleischmann RL, Hill CL, et al: The Yale-Brown ObsessiveCompulsive Scale. I. Development, use, and reliability. Arch Gen Psychiatry 46:1006-1011, 1989

19. Gorman DA, Thompson N, Plessen KJ, Robertson MM, Leckman JF, Peterson BS: Psychosocial outcome and psychiatric comorbidity in older adolescents with Tourette syndrome: controlled study. Br J Psychiatry 197:36-44, 2010

20. Goussé V, Czernecki V, Denis P, Stilgenbauer JL, Deniau E, Hartmann A: Impact of perceived stress, anxiety-depression and social support on coping strategies of parents having a child with Gilles de la Tourette syndrome. Arch Psychiatr Nurs 30:109-113, 2016

21. Guyatt GH, Oxman AD, Vist G, Kunz R, Brozek J, AlonsoCoello P, et al: GRADE guidelines: 4. Rating the quality of evidence-study limitations (risk of bias). J Clin Epidemiol 64:407-415, 2011

22. Hamilton M: A rating scale for depression. J Neurol Neurosurg Psychiatry 23:56-62, 1960

23. Hariz MI, Robertson MM: Gilles de la Tourette syndrome and deep brain stimulation. Eur J Neurosci 32:1128-1134, 2010

24. Hashemiyoon R, Kuhn J, Visser-Vandewalle V: Putting the pieces together in Gilles de la Tourette syndrome: explor- 
ing the link between clinical observations and the biological basis of dysfunction. Brain Topogr 30:3-29, 2017

25. Hassler R, Dieckmann G: [Stereotaxic treatment of tics and inarticulate cries or coprolalia considered as motor obsessional phenomena in Gilles de la Tourette's disease.] Rev Neurol (Paris) 123:89-100, 1970 (Fr)

26. Hauseux PA, Cyprien F, Cif L, Gonzalez V, Boulenger JP, Coubes P, et al: Long-term follow-up of pallidal deep brain stimulation in teenagers with refractory Tourette syndrome and comorbid psychiatric disorders: about three cases. Eur J Paediatr Neurol 21:214-217, 2017

27. Huasen B, McCreary R, Evans J, Potter G, Silverdale M: Cervical myelopathy secondary to Tourette's syndrome managed by urgent deep brain stimulation. Mov Disord 29:452-453, 2014

28. Huys D, Bartsch C, Koester P, Lenartz D, Maarouf M, Daumann J, et al: Motor improvement and emotional stabilization in patients with Tourette syndrome after deep brain stimulation of the ventral anterior and ventrolateral motor part of the thalamus. Biol Psychiatry 79:392-401, 2016

29. Jitkritsadakul O, Bhidayasiri R, Kalia SK, Hodaie M, Lozano AM, Fasano A: Systematic review of hardware-related complications of deep brain stimulation: do new indications pose an increased risk? Brain Stimul 10:967-976, 2017

30. Kaido T, Otsuki T, Kaneko Y, Takahashi A, Omori M, Okamoto T: Deep brain stimulation for Tourette syndrome: a prospective pilot study in Japan. Neuromodulation 14:123-129, 2011

31. Kurlan R: Clinical practice. Tourette's syndrome. N Engl J Med 363:2332-2338, 2010

32. Leckman JF: Tourette's syndrome. Lancet 360:1577-1586, 2002

33. Leckman JF, Riddle MA, Hardin MT, Ort SI, Swartz KL, Stevenson J, et al: The Yale Global Tic Severity Scale: initial testing of a clinician-rated scale of tic severity. J Am Acad Child Adolesc Psychiatry 28:566-573, 1989

34. Lipsman N, Ellis M, Lozano AM: Current and future indications for deep brain stimulation in pediatric populations. Neurosurg Focus 29(2):E2, 2010

35. Massano J, Sousa C, Foltynie T, Zrinzo L, Hariz M, Vaz R: Successful pallidal deep brain stimulation in 15-year-old with Tourette syndrome: 2-year follow-up. J Neurol 260:24172419, 2013

36. Mink JW, Walkup J, Frey KA, Como P, Cath D, Delong MR, et al: Patient selection and assessment recommendations for deep brain stimulation in Tourette syndrome. Mov Disord 21:1831-1838, 2006

37. Motlagh MG, Smith ME, Landeros-Weisenberger A, Kobets AJ, King RA, Miravite J, et al: Lessons learned from openlabel deep brain stimulation for Tourette syndrome: eight cases over 7 years. Tremor Other Hyperkinet Mov (N Y) 3:tre-03-170-4428-1, 2013

38. Müller-Vahl KR, Cath DC, Cavanna AE, Dehning S, Porta M, Robertson MM, et al: European clinical guidelines for Tourette syndrome and other tic disorders. Part IV: deep brain stimulation. Eur Child Adolesc Psychiatry 20:209-217, 2011

39. Murphy TK, Lewin AB, Storch EA, Stock S: Practice parameter for the assessment and treatment of children and adolescents with tic disorders. J Am Acad Child Adolesc Psychiatry 52:1341-1359, 2013

40. Nair G, Evans A, Bear RE, Velakoulis D, Bittar RG: The anteromedial GPi as a new target for deep brain stimulation in obsessive compulsive disorder. J Clin Neurosci 21:815-821, 2014

41. Nangunoori R, Tomycz ND, Quigley M, Oh MY, Whiting DM: Deep brain stimulation for psychiatric diseases: a pooled analysis of published studies employing disease-spe- cific standardized outcome scales. Stereotact Funct Neurosurg 91:345-354, 2013

42. Neudorfer C, El Majdoub F, Hunsche S, Richter K, Sturm V, Maarouf M: Deep brain stimulation of the $\mathrm{H}$ fields of forel alleviates tics in Tourette syndrome. Front Hum Neurosci 11:308, 2017

43. Patel N, Jimenez-Shahed J: Simultaneous improvement of tics and parkinsonism after pallidal DBS. Parkinsonism Relat Disord 20:1022-1023, 2014

44. Piedimonte F, Andreani JC, Piedimonte L, Micheli F, Graff P, Bacaro V: Remarkable clinical improvement with bilateral globus pallidus internus deep brain stimulation in a case of Lesch-Nyhan disease: five-year follow-up. Neuromodulation 18:118-122, 2015

45. Porta M, Saleh C, Zekaj E, Zanaboni Dina C, Bona AR, Servello D: Why so many deep brain stimulation targets in Tourette's syndrome? Toward a broadening of the definition of the syndrome. J Neural Transm (Vienna) 123:785-790, 2016

46. Porta M, Servello D, Zanaboni C, Anasetti F, Menghetti C, Sassi M, et al: Deep brain stimulation for treatment of refractory Tourette syndrome: long-term follow-up. Acta Neurochir (Wien) 154:2029-2041, 2012

47. Robertson MM, Cavanna AE, Eapen V: Gilles de la Tourette syndrome and disruptive behavior disorders: prevalence, associations, and explanation of the relationships. J Neuropsychiatry Clin Neurosci 27:33-41, 2015

48. Sachdev PS, Mohan A, Cannon E, Crawford JD, Silberstein P, Cook R, et al: Deep brain stimulation of the antero-medial globus pallidus interna for Tourette syndrome. PLoS One 9:e104926, 2014

49. Savica R, Stead M, Mack KJ, Lee KH, Klassen BT: Deep brain stimulation in Tourette syndrome: a description of 3 patients with excellent outcome. Mayo Clin Proc 87:59-62, 2012

50. Schrock LE, Mink JW, Woods DW, Porta M, Servello D, Visser-Vandewalle V, et al: Tourette syndrome deep brain stimulation: a review and updated recommendations. Mov Disord 30:448-471, 2015

51. Servello D, Sassi M, Gaeta M, Ricci C, Porta M: Tourette syndrome (TS) bears a higher rate of inflammatory complications at the implanted hardware in deep brain stimulation (DBS). Acta Neurochir (Wien) 153:629-632, 2011

52. Servello D, Zekaj E, Saleh C, Zanaboni Dina C, Porta M: Sixteen years of deep brain stimulation in Tourette's syndrome: a critical review. J Neurosurg Sci 60:218-229, 2016

53. Shahed J, Poysky J, Kenney C, Simpson R, Jankovic J: GPi deep brain stimulation for Tourette syndrome improves tics and psychiatric comorbidities. Neurology 68:159-160, 2007

54. Spielberger, CD, Gorsuch RL, Lushene PR, Vagg PR, Jacobs GA: Manual for the State-Trait Anxiety Inventory. Palo Alto, CA: Consulting Psychologists Press, 1983

55. Steeves T, McKinlay BD, Gorman D, Billinghurst L, Day L, Carroll A, et al: Canadian guidelines for the evidence-based treatment of tic disorders: behavioural therapy, deep brain stimulation, and transcranial magnetic stimulation. Can J Psychiatry 57:144-151, 2012

56. Stewart LA, Tierney JF: To IPD or not to IPD? Advantages and disadvantages of systematic reviews using individual patient data. Eval Health Prof 25:76-97, 2002

57. Testini P, Min HK, Bashir A, Lee KH: Deep brain stimulation for Tourette's syndrome: the case for targeting the thalamic centromedian-parafascicular complex. Front Neurol 7:193, 2016

58. Wårdell K, Kefalopoulou Z, Diczfalusy E, Andersson M, Aström M, Limousin P, et al: Deep brain stimulation of the pallidum internum for Gilles de la Tourette syndrome: a patient-specific model-based simulation study of the electric field. Neuromodulation 18:90-96, 2015 
59. Zabek M, Sobstyl M, Koziara H, Dzierzecki S: Deep brain stimulation of the right nucleus accumbens in a patient with Tourette syndrome. Case report. Neurol Neurochir Pol 42:554-559, 2008

60. Zekaj E, Saleh C, Porta M, Servello D: Temporary deep brain stimulation in Gilles de la Tourette syndrome: a feasible approach? Surg Neurol Int 6:122, 2015

61. Zhang JG, Ge Y, Stead M, Zhang K, Yan SS, Hu W, et al: Long-term outcome of globus pallidus internus deep brain stimulation in patients with Tourette syndrome. Mayo Clin Proc 89:1506-1514, 2014

\section{Disclosures}

Dr. Kalia: speaker's fees and honorarium from Medtronic. Dr. Lozano: consultant for Medtronic, St. Jude Medical, and Boston Scientific.

\section{Author Contributions}

Conception and design: Ibrahim, Elkaim. Acquisition of data: Coulombe, Elkaim. Analysis and interpretation of data: Ibrahim, Coulombe. Drafting the article: Coulombe. Critically revising the article: Elkaim, Alotaibi, Gorman, Weil, Fallah, Kalia, Lipsman, Lozano. Approved the final version of the manuscript on behalf of all authors: Ibrahim. Statistical analysis: Ibrahim, Coulombe. Study supervision: Ibrahim.

\section{Correspondence}

George M. Ibrahim: The Hospital for Sick Children, Toronto, ON, Canada. george.ibrahim@sickkids.ca. 